\title{
Competency Based Vocational Student Comprehensive Quality Evaluation
}

\author{
Yanping Cui ${ }^{1,}$, , Juan Gao, Zhizhi Yan, Xiaowei Wang \\ ${ }^{1}$ Wuhan Mechanical College, Wuhan 430075, China. \\ atangsengwang163@163.com
}

\begin{abstract}
The oversea study about comprehensive quality of vocational students, the differences between vocational education and college education, the features of professional quality, educational evaluation principal are introduced. An indicator System of vocational students' comprehensive quality evaluation is set up with two levels. And then, the organization system of vocational students' comprehensive quality evaluation is presented. At last, a fuzzy neural network model of comprehensive quality evaluation of vocational student is set up.
\end{abstract}

Keywords: Education evaluation; comprehensive quality; competency based; neural networks.

\section{Introduction}

Recently, with the rapid development of technology, the study about vocational education has made huge progress not only in developed countries but also in some of Asian countries.

In America, the newly comprehensive quality concept is considered as comprehensive reflection of a variety of capabilities. The vocational colleges pay more attention to the ability of learning, with which the students have the basic for lifelong learning.

In Korea, the comprehensive quality includes professional competence and basic skills. These basic skills are logical thinking ability, analysis ability, systems thinking, computing ability, cooperative ability and the capability to use computer.

Professor Dayuan Jiang considers that the foundations for the competency based vocational education are the below three kinds of abilities: professional competence, method ability, social skills. These three kinds of abilities are the components of the professional qualities.

According to the principles (McClelland, 1973), knowledge and skill are easy to measure, which are also relatively easy to develop by training. Both of them are "above section of iceberg" or dominant qualities. "The below sections of iceberg" or recessive qualities include social roles, self-concept, traits and motives. In concrete working position, dominant qualities are the skills and knowledge that are easy to grasp through learning and training and easy to be assessed and verified.

Ralph W. Tyler has been called by some as "the father of educational evaluation and assessment." He describes learning as taking place through the action of the student. "It is what he does that he learns, not what the teacher does".

\section{The Organization System of Vocational Students' Comprehensive Quality Evaluation}

The office of education affairs is responsible for organizing the evaluation of student comprehensive quality. The evaluation is implemented by the Department or school.

\subsection{The Organization of Evaluation.}

- Each Faculty sets up a leading group of student's comprehensive quality evaluation. The leader group should be composed by Dean, associate deans, and college counselors.

- Each faculty should develop the implementation details according to the specific circumstances.

- One class is an evaluation unit; the evaluation should be instructed by the college counselor.

- Each time the evaluation is finished, the results should be inputted into the database with computer, and the results should be authorized by the office of education affairs. 


\subsection{The Evaluation Workflow.}

- Personal declaration: students write personal self-assessment summary and submit the relevant application materials.

- Evaluation in class: Class evaluation team and counselor audit the self-assessment material.

- Publicity in class: The class evaluation results should be open accessed in the website, under the supervision by students.

- Confirmation by signature: after the expiration of publicity, the evaluation results should be submitted to the department.

- Department audition: The Department Office handed class evaluation results. Department Office will review the results of the initial evaluation of each class based on the evaluation criteria established by the department.

- Publicity in department: The results of the audit of the Department should be open accessed in department.

- College audition: the office of education affairs of college audits the results submitted by all departments. And then, the results should be reported to the headmaster. With the signature of headmaster, the results are valid (Fig. 1).

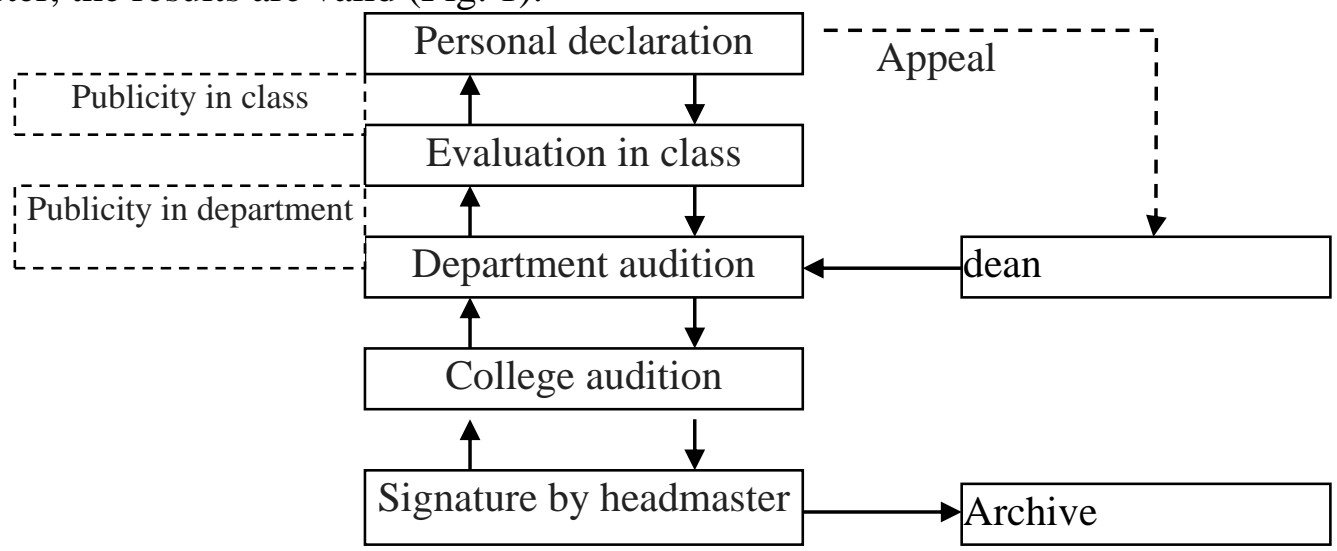

Fig. 1 The evaluation workflow

\section{Indicator System of Vocational Students' Comprehensive Quality Evaluation}

Vocational students' comprehensive quality evaluation is to evaluate the performances of vocational students. Only the evaluation is dependable and exactly can it is used for appraised selection. Otherwise, the emotion and motivation of students will be cut down. Therefore, we should analyze the characteristics of quality evaluation firstly, and then, a reasonable evaluation system will be set up (Table 1).

Table 1 Indicator system for evaluation

\begin{tabular}{|c|c|c|}
\hline target & $\begin{array}{l}\text { first-level } \\
\text { indicators }\end{array}$ & second-level indicators \\
\hline \multirow{4}{*}{$\begin{array}{l}\text { Vocational } \\
\text { students' } \\
\text { comprehensive } \\
\text { quality( } \\
\text { mechanical } \\
\text { engineering ) } \\
\text { (A) }\end{array}$} & $\begin{array}{l}\text { ideological } \\
\text { quality } \\
\text { (B1) }\end{array}$ & $\begin{array}{l}\text { Political discipline }(\mathrm{C} 1) \text { Collectivism }(\mathrm{C} 2) \\
\text { Moral character (C3) Dedication (C4) } \\
\text { responsibility (C5)Safety awareness (C6) }\end{array}$ \\
\hline & $\begin{array}{l}\text { professional } \\
\text { qualities (B2) }\end{array}$ & $\begin{array}{c}\text { Maintenance capability (C10) Operation skills }(\mathrm{C} 11) \\
\text { Equipment knowledge }(\mathrm{C} 12) \text { organizational capacity }(\mathrm{C} 13) \\
\text { Self-learning ability }(\mathrm{C} 14)\end{array}$ \\
\hline & $\begin{array}{l}\text { Basic } \\
\text { knowledge } \\
\text { (B3) }\end{array}$ & $\begin{array}{c}\text { Cultural enrichment (C15) Basic course knowledge (C16) } \\
\text { Basic specialized skills (C17)Innovation (C18) } \\
\text { Practical ability (C19) Scientific attitude (C20) } \\
\text { Humanities (C21) }\end{array}$ \\
\hline & $\begin{array}{l}\text { physical and } \\
\text { mental qualities } \\
\text { (B4) }\end{array}$ & $\begin{array}{l}\text { Physical condition (C22) Health Behavior (C23) } \\
\text { Emotion regulation (C24) PAA disposal (C25) }\end{array}$ \\
\hline
\end{tabular}


Vocational students' comprehensive quality evaluation system is consisted by the four categories performance indicators: ideological quality, professional qualities, physical and mental qualities. These four first-level indicators can be further subdivided into second-level indicators. The results of this research are presented by our project group, as shown in Table 1.

\section{Collection of Indicator Data}

\subsection{Collection of Quantitative Indicator Data.}

Collection of quantitative indicator data is primarily based on the evaluation of the student's behavior. This kind of data records the whole process of students' study and life and grade the performance with standard. The scores of basic knowledge and skills are given by teachers are also needed to be weighted by academic credit. Some subjects are marked as \{excellent, good, medium, pass, fail \}. These marks are also weighted by academic credit.

\subsection{Collection of Qualitative Indicator Data.}

The qualitative data is harder to collect than the quantitative data. The qualitative data is susceptible to people, such as classmates. It's vital to collect this kind of data objectively. Most of this kind of data cannot be measured by machine or instrument. But, the individual human qualities can be measured indirectly by the behavior and the objective affection. The school instructor and classmates will grade this kind of indicators, and the school instructor will be allocated more weight than classmate.

Some indicators can be evaluated by questionnaire, such as Safety awareness (C6) and Innovation (C18). The questionnaire will be answered by students' themselves on either paper or website. The well-designed questionnaire is always accurate.

\subsection{Implementation of Data's Collection.}

The keystone of setting up a useful indicator system is to collect the dependable data. The data can be collected each year or semester. It depends on the school. The class is the best unit for data's collection. The school instructor and the monitor should be responsible for the collection. All the data should be open to all the memberships of class.

\section{A Fuzzy Neural Network Model of Comprehensive Quality Evaluation}

After all the data are inputted into the database according to the indicator system of vocational students' comprehensive quality evaluation. How to draw the conclusion about each student is an important issue. In this paper, a neural network model of comprehensive quality evaluation is presented.

\subsection{Characteristic Analyses Comprehensive Quality Evaluation.}

The assessment indicator system is composed of first-level indexes and second-level indexes. The first indexes include second indexes, as shown in Table 1. The relation is fuzzy between the indexes and the conclusion, and the relationship cannot be judged only by "good" or "bad". So, it's improper to evaluate comprehensive quality of vocational students in normal way. Fuzzy mathematics can be used to solve this kind of fuzzy problem. Here, artificial neural network and fuzzy algorithm are used to evaluate the comprehensive quality.

\subsection{Establish Basic Data Model.}

$\mathrm{X}$ is the target set of comprehensive quality of a vocational student. $\mathrm{S}=\left\{\mathrm{s}_{1}, \mathrm{~s}_{2}, \mathrm{~s}_{3} \ldots \mathrm{s}_{\mathrm{k}}\right\}$, and $\mathrm{S}$ is the set of evaluate experts. For anyone of evaluate samples $x \in X . U=\left\{u_{1}, u_{2}, u_{3}, \ldots u_{n}\right\}$, and $U$ is the set of evaluate indexes. $V=\left\{v_{1}, v_{2}, v_{3} \ldots v_{m}\right\}$, and $V$ is the set of evaluation grade. $R$ is the fuzzy relationship of $U \times V . R\left(U_{i}, V_{j}\right)=r_{i j}\left(r_{i j} \in[0,1]\right)$. It means the fuzzy level between $u_{i}$ and $v_{j} . R=\left(r_{i j}\right)_{n \times m}$ is a $n \times m$ order matrix. The possibility of experts $S_{t}$ gives the comment $v_{j}(j=1,2, \ldots, m)$ is $\left.R_{i j}^{(t)} \in[0,1]\right)$, and there is an evaluation matrix $\left(R_{i j}^{(t)}\right)_{n \times m}$. What's more, $\sum_{j=1}^{m} r_{i j}^{(t)}=1$ 。

Then the evaluation matrix can be confirmed. $\mathrm{R}=\left(\mathrm{r}_{\mathrm{ij}}\right)_{\mathrm{n} \times \mathrm{m}}$, 


$$
r_{i j}=\sum_{\tau=1}^{k} \alpha_{\tau} r_{i j}^{(\tau)}\left(\sum_{t=1}^{k} \alpha_{t}\right)^{-1}, i=1,2, \ldots, n ; j=1,2, \ldots, m
$$

The fuzzy matrix above can be converted into $\mathrm{R}_{\mathrm{i}}(\mathrm{i}=1,2, \ldots, \mathrm{n})$ by the centroid method.

$$
R_{i}=\frac{\sum_{j=1}^{m} \beta_{j} r_{i j}}{\sum_{j=1}^{m} \alpha_{i}}=\sum_{j=1}^{m} \beta_{j} r_{i j}
$$

The comprehensive evaluation matrix $R=\left(r_{i j}\right)_{n \times 1}$ can be derived, $\beta_{j} \in[0,1](j=1,2, \ldots, m)$. $\beta_{j}$ means the importance of comment j. $\Sigma \beta_{\mathrm{j}}$ must not equal to 1 here.

\subsection{Set up the Fuzzy Evaluation System Based on Neural Network.}

Presumed $\mathrm{p}$ is the number of sample sets have been confirmed by experts ( $\mathrm{X}^{\prime}$ is a subset of $\mathrm{X}$ ). By expressions (1) and (2), evaluation matrix $\mathrm{R}=\left(\mathrm{r}_{\mathrm{i}}\right)_{\mathrm{n} \times 1}$ can be derived. At the same time, the result is also derived. $\mathrm{W}$ can be derived in the method of artificial neural network.

Operation "o" can use one of various fuzzy operators, and it depends on the circumstances and operating effect.

$\mathrm{W}=\mathrm{E}_{\mathrm{y}} \mathrm{Or}$

Evaluation matrix $\mathrm{R}=\left(\mathrm{r}_{\mathrm{ij}}\right)_{\mathrm{n} \times 1}$ is inputted into trained neural network. The result of comprehensive assessment $\mathrm{Y}$ can be derived through fuzzy neural network. $\overline{\mathrm{o}}$ is inverse operation of $\mathrm{o}$.

$$
\mathrm{Y}=\mathrm{w} \overline{\mathrm{o}} \mathrm{R}
$$

\section{Summary}

The BP neural network to evaluate the comprehensive quality of vocational students is an attempt to learn from nature. The accuracy of evaluation is vital. Based on the organization system of vocational students' comprehensive quality evaluation, the basic data can be collected and it's credible. In this paper, fuzzy neural network is used to evaluate the comprehensive quality of vocational students, the evaluation results are accurate and reliable, the evaluation process is simple and convenient.

\section{References}

[1]. McClelland, David C. "Testing for competence rather than for" intelligence."." American psychologist 28.1 (1973): 1.

[2]. McClelland, David C. "Identifying competencies with behavioral-event interviews." Psychological Science 9.5 (1998): 331-339.

[3]. Gronlund, Norman E. Assessment of student achievement. Allyn \& Bacon Publishing, Longwood Division, 160 Gould Street, Needham Heights, MA 02194-2310; tele, 1998.

[4]. Tyler, Ralph W. Basic principles of curriculum and instruction. University of Chicago press, 2013.pp.63-69

[5]. A. Corazza, S. Martino, V. Maggio, A. Moschitti, A. Passerini, G. Scanniello, F. Silvestri: in Proceedings of the Second International Workshop on Trustworthy Eternal Systems via Evolving Software (EternalS,2012), ,p. 117-134 